\title{
ОПРЕДЕЛЕНИЕ ПОЛИСАХАРИДОВ В РАСТИТЕЛЬНОМ СЫРЬЕ И ПРЕПАРАТАХ ЛИГНИНА
}

\author{
(C) Э.И. Евстигнеев
}

\author{
Санкт-Петербургский государственный лесотехнический университет, \\ Институтский пер., 5, Санкт-Петербург, 194021 (Россия), \\ e-mail: edward_evst@mail.ru
}

\begin{abstract}
Исследованы возможности фенол-сернокислотного метода для анализа растительного сырья. Установлено, что метод позволяет относительно просто и с высокой точностью определять полисахариды как в растительном сырье (сельскохозяйственных растениях и древесине хвойных и лиственных пород), так и в различных препаратах лигнина (мягковыделенных и технических). В основе метода лежит цветная реакция моносахаридов с фенолом в присутствии концентрированной серной кислоты. Разработанная модификация фенол-сернокислотного метода является универсальной в том смысле, что позволяет определять полисахариды в образцах как с высоким содержанием полисахаридов (растительное сырье), так и с низким (препараты лигнина). Метод обладает высокой чувствительностью: концентрация моносахаридов в смеси, приготовленной для анализа, составляет в среднем $1 \cdot 10^{-4}$ моль л $^{-1}$. Для анализа достаточно $0,25 \mathrm{~cm}^{3}$ гидролизата, предварительно разбавленного в 10 раз. Продолжительность анализа гидролизата, включающая в себя подготовку смеси, запись спектра и расчет по формуле, не превышает 30 мин. Метод может быть использован для анализа химического состава возобновляемого растительного сырья при разработке технологий получения альтернативных источников энергии.

Ключевые слова: фенол-сернокислотный метод, возобновляемое растительное сырье, полисахариды, моносахариды, лигнин.
\end{abstract}

Работа выполнена при финансовой поддержке РНФ (грант № 14-13-00448).

\section{Введение}

В связи с истощением ископаемых невозобновляемых ресурсов (нефти, газа, угля) в последние годы идет интенсивный поиск альтернативных источников энергии и химикатов для органического синтеза. В качестве такой альтернативы рассматривается возобновляемое растительное сырье, в том числе древесина. Предложена концепция «biomass refinery», предусматривающая полное комплексное использование всех компонентов биомассы дерева [1].

С целью получения альтернативного топлива разработаны и успешно развиваются технологии получения биоэтанола [2] и биобутанола [3]. В основе обоих процессов лежит кислотный или ферментативный гидролиз растительного сырья с последующей биохимической переработкой гидролизатов. Концепция «biomass refinery» включает в себя использование не только полисахаридов, но и лигнина, причем в технологии переработки и использования лигнина полисахариды являются нежелательной примесью [1]. В связи с этим количественное определение полисахаридов в растительном сырье и технических лигнинах является актуальной проблемой.

В настоящее время содержание и состав полисахаридов в древесине и сельскохозяйственных растениях определяют главным образом хроматографическими методами после предварительного кислотного гидролиза анализируемого образца [4]. Наиболее широкое распространение получила методика Теандера [5], включающая в себя следующие стадии: предварительную экстракцию образца, кислотный гидролиз, нейтрализацию гидролизата, восстановление и ацетилирование моносахаридов, экстракцию полученных

Евстигнеев Эдуард Иванович - профессор кафедры технологии лесохимических продуктов, химии древесины и физической химии, доктор химических наук, e-mail: edward_evst@mail.ru альдитолацетатов с последующим газохроматографическим анализом. Метод достаточно сложный, многостадийный, требующий калибровки 
и предусматривающий использование стандартных образцов. Общее содержание полисахаридов определяют, суммируя результаты анализа моносахаридов в расчете на индивидуальные полисахариды.

Цель данного исследования - разработка методики количественного определения общего содержания полисахаридов в растительном сырье и препаратах лигнина.

\section{Экспериментальная часть}

В основе предлагаемого метода лежит цветная реакция моносахаридов с фенолом в присутствии серной кислоты [6]. В результате предварительных исследований, направленных на определение оптимальных условий гидролиза анализируемого образца и количественного определения продуктов реакции, разработана следующая методика.

Образец растительного сырья (5 г) с размером частиц 0,25 мм экстрагировали этиловым спиртом (95\%) в аппарате Сокслета в течение 6 ч (30 сливов) и после отгонки растворителя на роторном испарителе и сушки колбы определяли содержание экстрактивных веществ.

К обессмоленному образцу (1 г) добавляли $15 \mathrm{~cm}^{3} 72 \% \mathrm{H}_{2} \mathrm{SO}_{4}$ и выдерживали при температуре $25{ }^{\circ} \mathrm{C}$ в течение 2,5 ч при периодическом перемешивании. По истечении указанного времени смесь переносили в колбу объемом $500 \mathrm{~cm}^{3}$, добавляли $200 \mathrm{~cm}^{3}$ дистиллированной воды и кипятили с обратным холодильником в течение 1 ч. Поскольку при анализе по описанной методике препаратов лигнина образуются очень мелкодисперсные осадки, проходящие через пористые стеклянные фильтры, для определения кислотонерастворимого лигнина (лигнина Класона) во всех образцах использовали известный методический прием [7].

Раствор с осадком лигнина фильтровали через сложенные вместе два уравновешенных на аналитических весах бумажных фильтра. Осадок лигнина и фильтры промывали водой из промывалки до полного удаления кислоты. Фильтры с лигнином сушили при температуре $103 \pm 2{ }^{\circ} \mathrm{C}$ до постоянной массы и взвешивали, помещая верхний фильтр (с лигнином) на левую чашку аналитических весов, а нижний - на правую. Здесь важно отметить, что фильтрат для последующего анализа на содержание кислоторастворимого лигнина и моносахаридов отбирали до стадии промывки. Кислоторастворимый лигнин определяли по методике из работы [8] при длине волны 205 нм.

Для определения полисахаридов $0,25 \mathrm{~cm}^{3}$ гидролизата (фильтрата), предварительно разбавленного в 10 раз, помещали в пробирку, вносили $1 \mathrm{~cm}^{3}$ раствора свежеперегнанного фенола с концентрацией 0,6 моль Л $^{-1}$ и $5 \mathrm{~cm}^{3}$ концентрированной $\mathrm{H}_{2} \mathrm{SO}_{4}$ («хч»), горячий раствор выдерживали в течение 10 мин, а затем охлаждали в течение 10 мин при температуре $25^{\circ} \mathrm{C}$. Затем в 1 см кюветах записывали УФ-спектр (рис.), используя в качестве раствора сравнения те же реагенты и в тех же концентрациях, что и в рабочем растворе, за исключением того, что вместо гидролизата добавляли $0,25 \mathrm{~cm}^{3}$ дистиллированной воды. УФспектры записаны на спектрофотометре UV-2400PC Series фирмы Shimadzu.

Содержание полисахаридов, \% к абсолютно сухому исходному (необессмоленному) образцу растительного сырья, рассчитывали по формуле:

$$
C=\frac{D \cdot K_{d} \cdot M_{m} \cdot V \cdot K_{p}}{\varepsilon \cdot 1000 \cdot g} \cdot K_{e} \cdot 100,
$$

где $D$ - оптическая плотность; $K_{d}$ - коэффициент разбавления; $M_{m}$ - молярная масса моносахарида, $\Gamma^{\cdot}$ моль ${ }^{-1}$ (гексозы 180,16 , пентозы 150,13$) ; V$ - объем гидролизата, см $^{3} ; K_{p}$ - коэффициент пересчета моносахаридов в полисахариды (для гексозанов - 0,9, для пентозанов - 0,88); $\varepsilon$ - молярный коэффициент экстинкции, л·моль ${ }^{-1} \cdot \mathrm{cm}^{-1} ; g$ - масса абсолютно сухой навески образца, г; $K_{e}-$ коэффициент экстрагирования.

\section{Обсуждение результатов}

С целью определения молярных коэффициентов экстинкции ( $\varepsilon$ ) по описанной методике исследовали образцы растительного сырья с известным химическим составом (табл. 1). В ней суммированы результаты, полученные в рамках международной программы Round-Robin on Whole Feedstock Analysis [4], одним из участников которой являлся и автор данной работы.

Судя по данным таблицы 1, в гидролизатах исследованных образцов содержатся гексозы (глюкоза, манноза, галактоза), пентозы (арабиноза, ксилоза) и глюкуроновая кислота в различных соотношениях в зависимости от вида растительного сырья. 
УФ-спектр гидролизата древесины сосны (Pinus radiata)

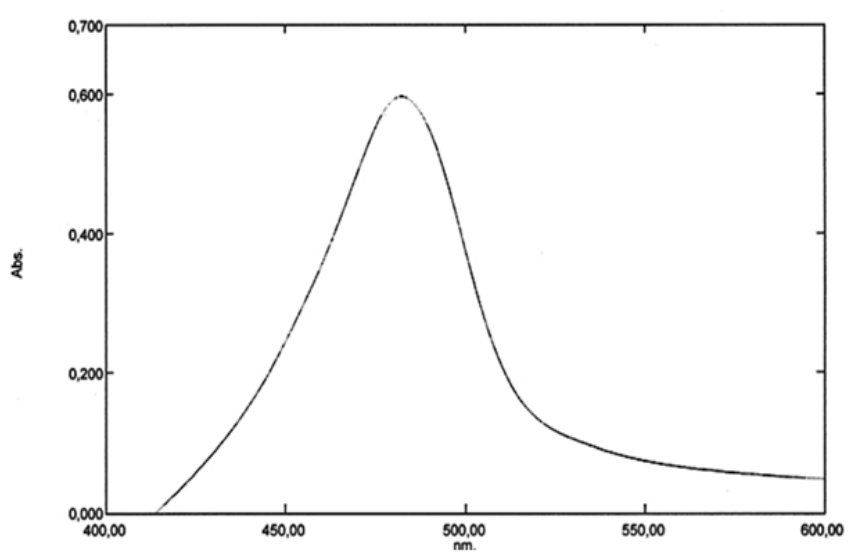

Таблица 1. Результаты анализа растительного сырья [4]

\begin{tabular}{|c|c|c|c|c|}
\hline \multirow{3}{*}{ Компонент } & \multicolumn{4}{|c|}{ Содержание компонента, \% } \\
\hline & \multicolumn{2}{|c|}{ древесина } & \multirow{2}{*}{ пшеничная солома } & \multirow{2}{*}{ багасса } \\
\hline & Populus deltoides & Pinus radiata & & \\
\hline Зола & 1,0 & 0,3 & 10,3 & 4,0 \\
\hline Экстрактивные вещества & 2,4 & 2,7 & 13,0 & 4,4 \\
\hline Лигнин & 25,6 & 25,9 & 15,7 & 23,1 \\
\hline Глюкуроновая кислота & 3,6 & 2,5 & 1,8 & 1,2 \\
\hline Арабинан & 0,6 & 1,5 & 2,2 & 1,7 \\
\hline Ксилан & 13,4 & 5,9 & 18,7 & 20,4 \\
\hline Маннан & 2,0 & 10,7 & 0,3 & 0,3 \\
\hline Галактан & 0,6 & 2,4 & 0,7 & 0,6 \\
\hline Глюкан & 42,2 & 41,7 & 32,9 & 38,6 \\
\hline Сумма компонентов & 91,4 & 93,6 & 95,6 & 94,3 \\
\hline Сумма полисахаридов & 58,8 & 62,2 & 54,8 & 61,6 \\
\hline
\end{tabular}

Очевидно, что оптическая плотность гидролизата зависит от состава моносахаридов, их концентрации и молярных коэффициентов экстинкции. В связи с этим в условиях определения полисахаридов исследовали оптические характеристики индивидуальных моносахаридов: D-глюкозы, D-маннозы, D-галактозы, L-aрабинозы, D-ксилозы и D-глюкуроновой кислоты («чда», дважды перекристаллизованные из этанола), с тем, чтобы определить вклад каждого моносахарида в общее поглощение гидролизатов растительного сырья. Состав и концентрации моносахаридов в них рассчитывали исходя из данных таблицы 1 и условий реакции гидролиза. Результаты представлены в таблице 2. Отметим, что для ксилозы первоначальное значение $\varepsilon$ скорректировано на поглощение фурфурола, в который она практически полностью превращается в условиях анализа [6].

Определение среднего значения молярного коэффициента экстинкции гидролизата $\left(\varepsilon_{c}\right)$ проводили исходя из вклада гексоз и пентоз в общее поглощение. В гидролизате лиственной древесины (Populus deltoides) их вклад приблизительно одинаков, поэтому усредняли значения $\varepsilon$ для всех соединений, присутствующих в растворе. Получили значение $\varepsilon_{c}=8400$ л•моль ${ }^{-1}$ см$^{-1}$ (табл. 3). В гидролизате хвойной древесины (Pinus radiata) вклад гексоз в общее поглощение гидролизата значительно выше $(0,74)$, чем пентоз $(0,26)$, поэтому усредняли значения $\varepsilon$ для гексоз и получили $\varepsilon_{c}=8050$ л·моль ${ }^{-1} \cdot \mathrm{cm}^{-1}$.

Хотя в гидролизате пшеничной соломы преобладают пентозы, тем не менее и для него более близкую к реальной величину при расчете общего содержания полисахаридов (табл. 4) позволяет получить использование $\varepsilon_{c}=8400$ л·моль ${ }^{-1} \cdot \mathrm{cm}^{-1}$. Вероятно, это связано с тем, что вклад отдельных моносахаридов в общее поглощение является не вполне аддитивным, поскольку положения максимумов поглощения гексоз и пентоз не совпадают и различаются на 10 нм (табл. 2).

Попытка использования этого коэффициента $\left(\varepsilon_{c}=8400\right.$ л·моль $\left.{ }^{-1} \cdot \mathrm{cm}^{-1}\right)$ для гидролизата багассы показала, что при расчете общего содержания полисахаридов получается несколько завышенный результат. В поисках причины указанного различия мы обратились к литературе и выяснили, что в гидролизатах багассы, помимо исследованных гексоз и пентоз, в сопоставимых с ними количествах содержится рамноза [9]. Определив ее оптические характеристики в тех же условиях $\left(\lambda_{\text {макс }}=478,4 \mathrm{Hм}, \varepsilon=15349\right.$ л $\cdot$ моль $\left.^{-1} \cdot \mathrm{cm}^{-1}\right)$ и учитывая это значение $\varepsilon$ при усреднении значений $\varepsilon$ для всех соединений, присутствующих в растворе, получили для гидролизата багассы $\varepsilon_{c}=9400$ л·моль ${ }^{-1} \cdot \mathrm{cm}^{-1}$. 
Таблица 2. Оптические характеристики растворов моносахаридов и глюкуроновой кислоты и их вклад в общее поглощение гидролизатов растительного сырья

\begin{tabular}{|c|c|c|c|c|c|c|}
\hline \multirow[b]{2}{*}{ Моносахарид } & \multirow[b]{2}{*}{$\lambda_{\text {макс }}, \mathrm{HM}$} & \multirow[b]{2}{*}{$\begin{array}{c}\varepsilon, \\
\text { л·моль }{ }^{-1} \cdot \mathrm{cm}^{-1}\end{array}$} & \multicolumn{4}{|c|}{ Вклад в общее поглощение, доля оптической плотности } \\
\hline & & & $\begin{array}{l}\text { Populus } \\
\text { deltoides }\end{array}$ & $\begin{array}{c}\text { Pinus } \\
\text { radiata }\end{array}$ & $\begin{array}{c}\text { пшеничная } \\
\text { солома }\end{array}$ & багасса \\
\hline Глюкоза & 487,6 & 3734 & 0,38 & 0,36 & 0,27 & 0,29 \\
\hline Манноза & 487,6 & 13683 & 0,07 & 0,34 & 0,01 & 0,01 \\
\hline Галактоза & 487,4 & 6729 & 0,01 & 0,04 & 0,01 & 0,01 \\
\hline Арабиноза & 476,8 & 11704 & 0,02 & 0,05 & 0,01 & 0,05 \\
\hline Ксилоза & 476,6 & 12764 & 0,51 & 0,21 & 0,63 & 0,64 \\
\hline Глюкуроновая кислота & 479,8 & 1815 & 0,01 & 0,01 & 0,01 & 0,01 \\
\hline
\end{tabular}

Таблица 3. Оптические характеристики гидролизатов растительного сырья

\begin{tabular}{l|c|c}
\multicolumn{1}{c|}{ Гидролизат } & $\lambda_{\text {макс, нм }}$ & $\varepsilon_{c}$, л $\cdot$ моль $^{-1} \cdot \mathrm{cm}^{-1}$ \\
\hline Populus deltoides & 479,6 & 8400 \\
Pinus radiata & 482,6 & 8050 \\
Пшеничная солома & 477,8 & 8400 \\
Багасса & 478,2 & 9400 \\
\hline
\end{tabular}

Таблица 4. Результаты определения полисахаридов и других компонентов растительного сырья

\begin{tabular}{|c|c|c|c|c|}
\hline \multirow{3}{*}{ Компонент } & \multicolumn{4}{|c|}{ Содержание компонента, \% } \\
\hline & \multicolumn{2}{|c|}{ древесина } & \multirow{2}{*}{ пшеничная солома } & \multirow{2}{*}{ багасса } \\
\hline & Populus deltoides & Pinus radiata & & \\
\hline Зола* & 1,0 & 0,3 & 10,3 & 4,0 \\
\hline Экстрактивные вещества & 2,6 & 3,1 & 13,0 & 3,3 \\
\hline Лигнин & 24,9 & 25,6 & 16,8 & 23,8 \\
\hline Глюкуроновая кислота* & 3,6 & 2,5 & 1,8 & 1,2 \\
\hline Сумма полисахаридов & $\mathbf{5 8 , 6}(0,3)$ & $\mathbf{6 2 , 4}(0,3)$ & $\mathbf{5 5 , 7}(1,6)$ & $\mathbf{5 9 , 6}(3,2)$ \\
\hline Сумма компонентов & 90,7 & 93,9 & 97,6 & 91,9 \\
\hline
\end{tabular}

"Данные из работы [4]. В скобках приведена относительная ошибка определения, \%.

Результаты проведенного нами исследования химического состава растительного сырья приведены в таблице 4. Они показывают, что разработанный метод анализа позволяет определять полисахариды с достаточно высокой точностью (относительная ошибка определения лежит в интервале 0,3-3,2\%). Для сравнения с литературными данными (см. табл. 1) в таблицу 4 включены также результаты определения экстрактивных веществ, лигнина и суммы всех компонентов.

Дополнительную проверку разработанного метода проводили при изучении химического состава древесины ели (Picea excelsa). Так же, как и Pinus radiata, она является хвойной породой, поэтому при расчете содержания полисахаридов использовали $\varepsilon_{c}=8050$ л моль ${ }^{-1} \cdot \mathrm{cm}^{-1}$. В результате получили значение $66,2 \%$. В соответствии с литературными данными [10] общий выход редуцирующих веществ при количественном гидролизе древесины ели составляет 72,5\%. При пересчете моносахаридов в полисахариды $\left(K_{p}=0,89\right)$ содержание последних составляет $64,5 \%$. Иными словами, и в этом случае относительная ошибка определения невелика $(2,6 \%)$.

Препараты лигнина ели исследовали по такой же методике, за исключением того, что они анализировались без предварительной экстракции, фильтрат после определения лигнина Класона не разбавляли, а навеска лигнина составила 0,3 г. Методы выделения лигнина описаны в работах: лигнин Фрейденберга [11], лигнин Бьеркмана [12], лигнин Пеппера [13], диоксанлигнин [14], гидролизный лигнин и окисленный гидролизный лигнин [15], натронный и сульфатный лигнины [16]. Результаты исследования приведены в таблице 5.

Литературные данные о содержании полисахаридов в лигнине немногочисленны. Среди мягковыделенных препаратов в этом смысле более подробно исследован лигнин Бьеркмана ели. В монографии [17] сообщается, что он может содержать от 2 до 8\% углеводов. При дополнительной очистке препарата, включающей в себя в том числе и обработку разбавленной щелочью, можно снизить содержание углеводов до 0,14-1,6\% [18]. На наш взгляд, использование для очистки лигнина щелочи, в которой он хорошо растворяется, неизбежно приведет к потере выхода лигнина, который при выделении по методу Бьеркмана составляет только $25 \%$ от лигнина Класона [17]. 
Таблица 5. Оптические характеристики гидролизатов и химический состав препаратов лигнина ели

\begin{tabular}{l|c|c|c|c|c|c}
\hline \multicolumn{1}{c|}{ Препарат } & $\lambda_{\text {макс, нм }}$ & $\begin{array}{c}\varepsilon_{c}, \text { л·моль } \\
{ }^{1} \cdot \mathrm{cm}^{-1}\end{array}$ & $\begin{array}{c}\text { Лигнин } \\
\text { Класона, } \%\end{array}$ & КРЛ, \% & ПС, \% & Сумма, \% \\
\hline Лигнин Фрейденберга & 486,8 & 8050 & 88,8 & 0,9 & 6,5 & 96,2 \\
Лигнин Бьеркмана & 485,6 & 8050 & 92,3 & 2,6 & 5,3 & 100,2 \\
Лигнин Пеппера & 484,2 & 8050 & 95,2 & 2,0 & 3,7 & 101,1 \\
Лигнин Пеппера & & & & & \\
окисленный & 482,8 & 8050 & 92,2 & 2,9 & 3,4 & 98,5 \\
Диоксанлигнин & 482,8 & 8050 & 90,2 & 3,2 & 2,1 & 95,5 \\
Гидролизный лигнин & 487,2 & 8050 & 88,1 & 0,8 & & 95,3 \\
Гидролизный лигнин & & & & & \\
окисленный & 486,4 & 8050 & 86,3 & 3,7 & 6,3 & 96,3 \\
Натронный лигнин & 478,4 & 8400 & 84,2 & 6,0 & 7,3 & 97,5 \\
Сульфатный лигнин & 479,6 & 8400 & 86,4 & 5,7 & 7,1 & 99,2 \\
\hline
\end{tabular}

Примечания: КРЛ - кислоторастворимый лигнин; ПС - полисахариды.

Содержание гексозанов в несколько раз превышает содержание пентозанов как в древесине ели [10], так и в лигнине Бьеркмана ели [18]. Поэтому при определении полисахаридов с помощью разработанного метода во всех препаратах лигнина использован один и то же коэффициент $\varepsilon_{c}=8050$ л·моль ${ }^{-1} \cdot \mathrm{cm}^{-1}($ табл. 5). Исключение составляют натронный и сульфатный лигнины. Причиной этого является состав полисахаридов указанных препаратов.

В отличие от других препаратов, они выделены из щелоков щелочных варок древесины. В этих условиях гемицеллюлозы частично растворяются, главным образом ксилан [19], и при последующем выделении лигнина соосаждаются с ним. Установлено, что в состав полисахаридов сульфатного лигнина сосны входит 69\% пентозанов и $31 \%$ гексозанов, а в состав натронного - соответственно 73 и 27\% [20]. Преобладание пентозанов в щелочных лигнинах подтверждается и близостью положения максимумов поглощения

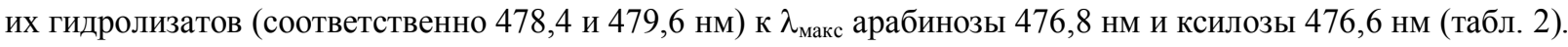
Поэтому для них использован коэффициент $\varepsilon_{c}=8400$ л·моль ${ }^{-1} \cdot \mathrm{cm}^{-1}$. С другой стороны, значения $\lambda_{\text {макс }}$ гидролизатов остальных препаратов лигнина характерны для гексоз.

Анализируя данные таблицы 5, можно заметить, что суммарное содержание лигнина Класона, кислоторастворимого лигнина и полисахаридов во всех препаратах близко к 100\%. Это является еще одним аргументом в пользу правильности использованной методики определения полисахаридов.

В заключение отметим, что разработанный метод анализа позволяет относительно просто и с высокой точностью определять полисахариды как в растительном сырье (древесине хвойных и лиственных пород и сельскохозяйственных растениях), так и в различных препаратах лигнина (мягковыделенных и технических), отличающихся сравнительно низким содержанием полисахаридов (2-7\%).

\section{Bblводы}

1. Фотоколориметрический метод, основанный на цветной реакции моносахаридов с фенолом в присутствии серной кислоты, позволяет относительно просто и достаточно надежно количественно определять полисахариды в древесине и сельскохозяйственных растениях, а также в препаратах лигнина.

2. Метод может быть использован для анализа химического состава возобновляемого растительного сырья при разработке технологий получения альтернативных источников энергии.

\section{Список литературы}

1. Monomers, Polymers and Composites from Renewable Resources / M.N. Belgacem, A. Gandini (eds.). Amsterdam etc.: Elsevier, 2008. 552 p.

2. Buruiană C.T., Garrote G., Vizireanu C. Bioethanol production from residual lignocellulosic materials. a review // AUDJG - Food Technology. 2013. Vol. 37, N1. Pp. 9-24.

3. Tao L., He X., Tan E.C.D., Zhang M., Aden A. Comparative techno-economic analysis and reviews of n-butanol production from corn grain and corn stover // Biofuels, Bioproducts and Biorefining. 2014. Vol. 8, N3. Pp. 342-361.

4. Milne T.A., Chum H.L., Agblevor F., Johnson D.K. Standardized analytical methods // Biomass and Bioenergy. 1992. Vol. 2, N1-6. Pp. 341-366.

5. Theander O. Chemical analysis of lignocellulose materials // Animal Feed Sci. Tech. 1991. Vol. 32, N1-3. Pp. 35-44.

6. Dubois M., Gilles K.A., Hamilton J.K., Rebers P.A., Smith F. Colorimetric method for determination of sugars and related substances // Analytical Chemistry. 1956. Vol. 28, N3. Pp. 350-356. 
7. Оболенская А.В., Ельницкая 3.П., Леонович А.А. Лабораторные работы по химии древесины и целлюлозы. M., 1991. $320 \mathrm{c}$

8. Swan B. Isolation of acidsoluble lignin from the Klason lignin determination // Svensk Papperstidn. 1965. Vol. 68, N22. Pp. 791-795.

9. Abo-Statea M.A., Ragabb A.M.E., EL-Gendyc N.S., Farahatc L.A., Madianc H.R. Effect of different pretreatments on egyptian sugar-cane bagasse saccharification and bioethanol production // Egyptian Journal of Petroleum. 2013. Vol. 22, N1. Pp. 161-167.

10. Шарков В.И., Куйбина Н.И., Соловьева Ю.П., Павлова Т.А. Количественный химический анализ растительного сырья. М., 1976. 72 с.

11. Freudenberg K. Lignin // Modern methods of plant analysis / K. Paech, M.V. Tracey (eds.). Berlin, 1955. Vol. 3. Pp. 499-516.

12. Björkman A. Studies on finely divided wood // Svensk Papperstidn. 1956. Vol. 59, N13. Pp. 477-485.

13. Pepper J.M., Baylis P.E.T., Adler E. The isolation and properties of lignins obtained by the acidolysis of spruce and aspen woods in dioxane-water medium // Canad. J. Chem. 1959. Vol. 37, N7. Pp. 1241-1248.

14. Lundquist K. Low-molecular weight lignin hydrolysis products // Appl. Polym. Symp. 1976. N28. Pp. $1393-1407$.

15. Евстигнеев Э.И. Окисление гидролизного лигнина пероксидом водорода в кислой среде // Журнал прикладной химии. 2013. Т. 86, вып. 2. С. 278-285.

16. Evstigneyev E., Maiyorova H., Platonov A. Lignin functionalization and the alkaline delignification rate // Anthraquinone pulping. A TAPPI Press anthology of published papers 1977-1996 / G.C. Goyal (ed.). Atlanta, 1997. Pp. 505-510.

17. Лигнины. Структура, свойства и реакции : пер. с англ. / под ред. К.В. Сарканена и К.Х. Людвига. М., 1975. 632 с.

18. Lundquist K., Simonson R., Tingsvik K. Lignin carbohydrate linkages in milled wood lignin preparations from spruce wood // Svensk Papperstidning. 1982. Vol. 86, N6. Pp. R44-R47.

19. Гемицеллюлозы / под ред. В.С. Громова и М.С. Дудкина. Рига, 1991. 488 с.

20. Gellerstedt G., Lindfors E-L. Structural changes in lignin during kraft pulping. Holzforschung // Holzforschung. 1984. Bd. 38, H. 3. S. 151-158. 
Evstigneyev E.I. QUANTIFICATION OF POLYSACCHARIDES IN VEGETABLE RAW MATERIALS AND LIGNIN PREPARATIONS

St. Petersburg State Forestry University, Institutskii per., 5, St. Petersburg, 194021 (Russia), e-mail:edward_evst@mail.ru

Opportunities phenol-sulfuric acid method for the analysis of vegetable raw materials are investigated. It is established that the method allows rather simply and with high precision to define polysaccharides as in vegetable raw materials (agricultural plants and softwood and hardwood), and in various preparations of a lignin (the laboratory-scale and technical). Color reaction of monosaccharides with phenol in the presence of the concentrated sulfuric acid is the basis of a method. The developed modification phenol - sulfuric acid method is universal in the sense that allows to define polysaccharides in samples as with the high content of polysaccharides (vegetable raw materials), and with low (lignin preparations). The method possesses high sensitivity: concentration of monosaccharides in the mix prepared for the analysis averages $1 \cdot 10^{-4} \mathrm{~mol} \cdot 1^{-1}$. For the analysis $0.25 \mathrm{~cm}^{3}$ of the hydrolyzate which is previously diluted by 10 times there are enough. Duration of the analysis of a hydrolyzate including mix preparation, record of a spectrum and calculation for a formula doesn't exceed 30 min. The method can be used for the analysis of a chemical composition of renewable vegetable raw materials when developing technologies of receiving alternative energy sources.

Keywords: phenol-sulfuric acid method, renewable vegetable raw materials, polysaccharides, monosaccharides, lignin.

\section{References}

1. Monomers, Polymers and Composites from Renewable Resources / M.N. Belgacem, A. Gandini (eds.). Amsterdam etc.: Elsevier. 2008. 552 p.

2. Buruiană C.T., Garrote G., Vizireanu C. AUDJG - Food Technology, 2013, vol. 37, no. 1, pp. 9-24.

3. Tao L., He X., Tan E.C.D., Zhang M., Aden A. Biofuels, Bioproducts and Biorefining, 2014, vol. 8, no. 3, pp. 342-361.

4. Milne T.A., Chum H.L., Agblevor F., Johnson D.K. Biomass and Bioenergy, 1992, vol. 2, no. 1-6, pp. 341-366.

5. Theander O. Animal Feed Sci. Tech., 1991, vol. 32, no. 1-3, pp. 35-44.

6. Dubois M., Gilles K.A., Hamilton J.K., Rebers P.A., Smith F. Analytical Chemistry, 1956, vol. 28, no. 3, pp. 350-356.

7. Obolenskaia A.V., El'nitskaia Z.P., Leonovich A.A. Laboratornye raboty po khimii drevesiny i tselliulozy. [Laboratory work on the chemistry of wood and cellulose]. Moscow, 1991, 320 p. (in Russ.).

8. Swan B. Svensk Papperstidn., 1965, vol. 68, no. 22, pp. 791-795.

9. Abo-Statea M.A., Ragabb A.M.E., EL-Gendyc N.S., Farahatc L.A., Madianc H.R. Egyptian Journal of Petroleum, 2013, vol. 22, no. 1, pp. 161-167.

10. Sharkov V.I., Kuibina N.I., Solov'eva Iu.P., Pavlova T.A. Kolichestvennyi khimicheskii analiz rastitel'nogo syr'ia. [Quantitative chemical analysis of the raw material]. Moscow, 1976, 72 p. (in Russ.).

11. Freudenberg K. Modern methods of plant analysis. K. Paech, M.V. Tracey (eds.). Berlin, 1955, vol. 3, pp. $499-516$.

12. Björkman A. Svensk Papperstidn., 1956, vol. 59, no. 13, pp. 477-485.

13. Pepper J.M., Baylis P.E.T., Adler E. Canad. J. Chem., 1959, vol. 37, no. 7, pp. 1241-1248.

14. Lundquist K. Appl. Polym. Symp., 1976, no. 28, pp. 1393-1407.

15. Evstigneev E.I. Zhurnal prikladnoi khimii, 2013, vol. 86, issue 2, pp. 278-285. (in Russ.).

16. Evstigneyev E., Maiyorova H., Platonov A. Anthraquinone pulping. A TAPPI Press anthology of published papers 1977-1996. G.C. Goyal (ed.). Atlanta, 1997.pp. 505-510.

17. Ligniny. Struktura, svoistva i reaktsii. [Lignins. The structure, properties and reactions]. Ed. K.V. Sarkanen and K.Kh. Liudvig. Moscow, 1975, 632 p. (in Russ.).

18. Lundquist K., Simonson R., Tingsvik K. Svensk Papperstidning, 1982, vol. 86, no. 6, pp. R44-R47.

19. Gemitselliulozy. [Hemicelluloses]. Ed. V.S. Gromov and M.S. Dudkin. Riga, 1991, 488 p. (in Russ.).

20. Gellerstedt G., Lindfors E-L. Holzforschung, 1984, bd. 38, h. 3, s. 151-158.

Received February 19, 2016 
